\title{
Reconceptualising the Role of the Visiting Lecturer: Using Educational Technology to Enable Practicum Placements In The 'New Normal'
}

\author{
Sarah Probine \\ Manukau Institute of Technology \\ sarah.probine@manukau.ac.nz \\ Jo Perry \\ Manukau Institute of Technology \\ jo.perry@manukau.ac.nz
}

Keywords: Initial teacher education; practicum; virtual meetings; reconceptualising teachers and learners roles.

\begin{abstract}
:
The international pandemic and the national lockdown during semester one of 2020 meant the Manukau Institute of Technology Early Childhood teams needed to revisit the existing requirements of their programmes and particularly in terms of practicum. In response, the teams developed 'virtual' meetings to replace the usual observation visit by a visiting lecturer. In this revised approach, the students and lecturers engaged in weekly conversations and in these meetings the role of the Visiting Lecturer was significantly changed. By using communication software (Microsoft Teams with cell phone back up) the student and Visiting Lecturer engaged in critically reflective conversations that mentored the student in thinking about their practice, setting goals to work on and articulating their learning. By using the software in this way, the Visiting Lecturers changed their role from merely assessor of practice to firstly, mentor and guide. In the online triadic meetings (also using Microsoft Teams and cell phone back-up) it became clear that the traditional model of the student being told how the assessor felt they had met the practicum criteria was replaced with one where the student was able to articulate for themselves.
\end{abstract}

At the end of the semester, students and lecturers were invited to give feedback via a survey. The responses focused on the deep learning experienced, ownership of learning, and the confidence the students felt at the online triadic. Much more unexpected was the correlation between survey responses and much of the literature. Drawing on these findings, this presentation poses some possibilities for what both the practicum and a reconceptualised relationship between visiting lecturer, associate teacher and students could look like in the 'new normal'. 